\title{
Spin-offs: Theory and Evidence from the Early U.S. Automobile Industry ${ }^{*}$
}

\author{
Luís Cabral \\ New York University and CEPR \\ Zhu Wang \\ Federal Reserve Bank of Richmond
}

November 2012

\begin{abstract}
We develop a "passive learning” model of firm entry by spin-off: firm employees leave their employer and create a new firm when (a) they learn they are good entrepreneurs (type I spin-offs) or (b) they learn their employer's prospects are bad (type II spin-offs). Our theory predicts a high correlation between spin-offs and parent exit, especially when the parent is a low-productivity firm. This correlation may correspond to two types of causality: spin-off causes firm exit (type I spin-offs) and firm exit causes spin-off (type II spin-offs). We test and confirm this and other model predictions on a unique data set of the U.S. automobile industry. Finally, we discuss policy implications regarding “covenant not to compete” laws.
\end{abstract}

\footnotetext{
* Cabral: Department of Economics, Stern School of Business, New York University, lcabral@stern.nyu.edu. Wang: Research Department, Federal Reserve Bank of Richmond, zhu.wang@rich.frb.org. The views expressed herein are solely those of the authors and do not necessarily reflect the views of the Federal Reserve Bank of Richmond or the Federal Reserve System. We thank Christian Hung for excellent research assistance.
} 


\section{Introduction}

In many industries, a considerable fraction of firm entry results from spin-offs, which we define as the situation when a firm's employee leaves his employer and starts a new firm in the same industry. For example, in the automobile industry and in the period 1895-1969, 18\% of all new firms were spin-offs of existing firms. This pattern suggests at least two questions: First, why do spin-offs take place? and second, do spin-offs lead to a socially efficient allocation of resources?

Recent research provides a series of answers to the first question. Klepper and Slepper (2002) and Klepper and Thompson (2005, 2006) propose a "disagreement" theory of spin-offs. If an employee's idea is not adopted by his employer, then the employee is likely to leave and create a firm where his idea can be implemented. Chatterjee and Rossi-Hansberg (2007) propose an adverse selection theory of spin-offs. To the extent that employees have better information about the value of their ideas, an adverse selection problem arises, the equilibrium of which is for owners of better ideas to start a new firm. Baccara and Razin (2006) present a theory whereby employees choose

to spin-off either because they fear the employer may expropriate the rents flowing from innovation or because the employer discourages innovation in favor of maintaining the existing intra-firm rent distribution. Finally, Franco and Filson (2006) stress the fact that employees acquire know-how while working for a firm and eventually capitalize on that know-how by starting their own firm.

Regarding the welfare impact of spin-offs, there are two important considerations. To the extent that exiting employees take ideas or other resources from their former employer, spin-offs may imply an equilibrium with underinvestment, as firms are reluctant to invest in ideas that will be stolen by their employees. By contrast, to the extent that employees increase their human capital while employed and then apply it to the creation of new value, spin-offs correspond to an efficient reallocation of resources. The relative magnitude of these two effects is an important policy question. Some states enforce "covenant not to compete" (CNC) laws based on the belief that the 
first effect dominates. ${ }^{1}$ However, authors such as Franco and Mitchell (2008) argue that CNC laws in Massachusetts may have caused Route 128 to be taken over by the Silicon Valley, suggesting that the value creation effect of spin-offs may be important.

In this paper, we present a novel theory of spin-offs. Our model implicitly or explicitly incorporates many of the features of previous theories of spinoffs. However, we extend the analysis in two important dimensions. First, in the tradition of Jovanovic's (1982) "passive learning" theory of industry evolution, we assume that firms learn their type over time; and to this we add the hypothesis that employees also learn their ability over time. In this context, spin-offs take place either because an employee learns that he would make a good entrepreneur (type I spin-off) or because he learns his employer's prospects are poor, and so the opportunity cost of leaving the firm is small (type II spin-off).

The second important contribution of our work is that, unlike the previous literature, we pay close attention to the interdependence between parent performance and spin-off performance as implied by our model. First, we show that spin-off entrants are more likely to survive than de novo entrants (because the group of spin-off entrants is biased toward higher types). Second, we show that spin-offs have a negative impact on the survival of low-type parents (because a spin-off implies that the parent loses talent which is better than market average). Third, we show that spin-offs originating from surviving parents perform better than spin-offs originating from dying parents (because the former are all high-type entrepreneurs but the latter include a mixture of high-type and low-type entrepreneurs). In sum, we show that sometimes spin-offs cause parent failure (type I spin-off), whereas in other cases parent failure causes spin-offs (type II spin-off).

We test these predictions on a dataset of the US automobile industry, focusing on the industry's early years (1895-1942). Anecdotal evidence suggests that both type I and type II spin-offs take place in this industry. An example of a type I spin-off is given by Lozier and Chandler. Lozier Motor Company started production in 1904. Its output peaked in the 1912

1. A covenant not to compete, also called a non-competitive clause, is a formal agreement requiring former employees not to perform similar work within a designated area for a specified amount of time after leaving their original employer. 
model year at 600 cars. Frederick C. Chandler, Lozier's top designer, left the company in 1913 (together with several top company executives) and formed the Chandler Motor Company. The impact of Chandler's departure was deeply felt at the parent company. Lozier never recovered from the brain drain and stopped production in 1914. After a failed attempt to merge with Ford Motor Company, it declared bankruptcy. Chandler Motor Company, by contrast, became a successful producer, peaking at 20,000 cars in 1927. In 1929, Chandler Motor Company was purchased by Hupp Motor Works.

An example of a type II spin-off is given by Emerson and Campbell. The Emerson Motor Company started production in 1917 with the goal of challenging the highly successful Ford Model T. In the process of allegedly raising capital for Emerson, several stock promoters obtained (and pocketed) more than $\$ 1,500,000$ under the promise that the company had a production capacity of 80,000 cars a year (which it didn't). Court proceeding were initiated against Emerson M C and four individuals, all of whom were found guilty of mail fraud. In September 1917, co-founders and brothers Campbell left the company and founded the Campbell Motor Company, which produced the the same car as Emerson. By May 1919, Campbell was on receivership.

Although anecdotal evidence gives credence to our theory, we seek further confirmation by means of econometric analysis. We show that our predictions are economically and statistically significant. Finally, we discuss policy implications, especially with regard to "covenant not to compete" (CNC) laws.

\section{Model}

Consider a competitive, homogeneous product industry with demand $D(p)$ and inverse demand $P(Y)$, where $p$ is price and $Y$ industry output. We assume that $\lim _{Y \rightarrow 0} P(Y)=\infty$ and $\lim _{p \rightarrow 0} D(p)=\infty$.

Market supply consists of a measure of atomless firms. Each firm is made up of two agents: a manager (also referred to as the "entrepreneur"), and an employee (also referred to as the "worker"). ${ }^{2}$ Each agent can be of two types:

2. While we use the terminology "worker," what we have in mind is a high-level, high-skill employee such as a leading designer, or engineer. 
Table 1: Timing: stages within each period.

$s=1$ Firm exit decisions (voluntary and involuntary).

$s=2$ Worker mobility (spin-offs and new hirings).

$s=3$ Firm entry decisions (insiders and outsiders).

$s=4$ Payoffs received (profits and wages).

$H$ (probability $\alpha$ at birth) and $L$ (probability $1-\alpha$ ), where $H>L$. Before entering the industry, an agent does not know its type, only the prior $\alpha$. Upon entering the industry (either as a manager or as a worker), an agent's type becomes common knowledge within the firm.

An active type $z$ firm earns a profit

$$
\pi_{z}=p y_{z}-\omega
$$

where $y_{z}$ is output level, $\omega$ the wage rate paid to the sole worker, and $z=$ $H H, H L, L H, L L$ represents the four possible types a firm can be: the first subscript denotes the manager's type and the second subscript denotes the worker's type. We assume that firm output is strictly increasing in manager type and in worker type; that is, $y_{z}=f(m, w)$, where $m$ is manager type and $w$ is worker type $(m, w=H, L)$, and $f(\cdot)$ is increasing in both arguments.

Letting $\mu_{z}$ be the measure of firms of type $z$, industry output is given by

$$
Y=\sum \mu_{z} y_{z}
$$

Time is discrete and continues on forever. Within each period, we consider four main stages (see Table 1). First, both nature and firm managers make exit decisions. Nature decides with probability $1-\gamma$ that the firm will exit by the end of the period. Even if the firm survives the Nature shock, the firm manager decides whether to exit or remain active.

In the second stage, workers in active firms must decide whether to continue as employees or rather leave the firm (to attempt a spin-off). If a worker leaves the firm, then the worker is replaced by a generic worker from the pool of potential entrants as workers. In particular, the new hire is of type $H$ with probability $\alpha$.

Decisions to create new firms take place during the third stage. By then there are three groups of potential entrepreneurs: former firm managers who 
decided to close down their firm, or were subject to a Nature shock; former workers who decided to leave the firm or became unemployed by virtue of their employer's exit; and potential first-time entrants. We call the first two groups the insiders, in the sense that they already have industry experience; and we call the third group the outsiders. This is an important distinction because the entry cost is different for insiders $(\phi)$ and for first-time entrants $(\psi+\phi>\phi)$. The idea is that part of the entry cost for a first-time entrant corresponds to an industry learning cost. Notice also that among the insiders we can also make a distinction between $H$ types and $L$ types.

By deciding to create a new firm, a would-be manager pays the entry cost $(\phi$ or $\psi+\phi)$ and is successful with probability $\rho$. Alternatively, agents may collect $\xi$ as an outside option. For simplicity, we also assume that unsuccessful entrepreneurs ( $1-\rho$ of those who try) stay with their employer (if there were employed) or otherwise leave the industry and collect their outside option payoff $\xi$.

Finally, during the fourth stage production payoffs are received: $\pi_{z}$ to the manager and $\omega$ to the worker.

There are a few implicit assumptions in this set-up which we should stress. First, we assume that wages are independent of the agent's type (or the manager's). In a more realistic model we might include some model of wage negotiation or wage market setting. However, to the extent that contracts are incomplete and/or the agent's type is unobservable or unverifiable, our assumption is not a bad approximation. It will also allows us to focus on the issues that the paper deals with primarily.

Second, we assume that manager and worker cannot trade places, nor can the manager fire the worker. Again, we think of this as a reduced-form of a more complex model where, due to information asymmetries, government regulation, or some other source of inefficiency, the only option open to managers is to close down the firm and the only option open to workers is to leave the firm.

Figure 1 helps understand the main flows of firms and agents in our model. In this figure, square "bins" represent firm types, whereas circular "bins" represent agent types (with $E$ denoting an entrant who still does not know his type).

The arrows in Figure 1 represent flows from one period to the next. They 


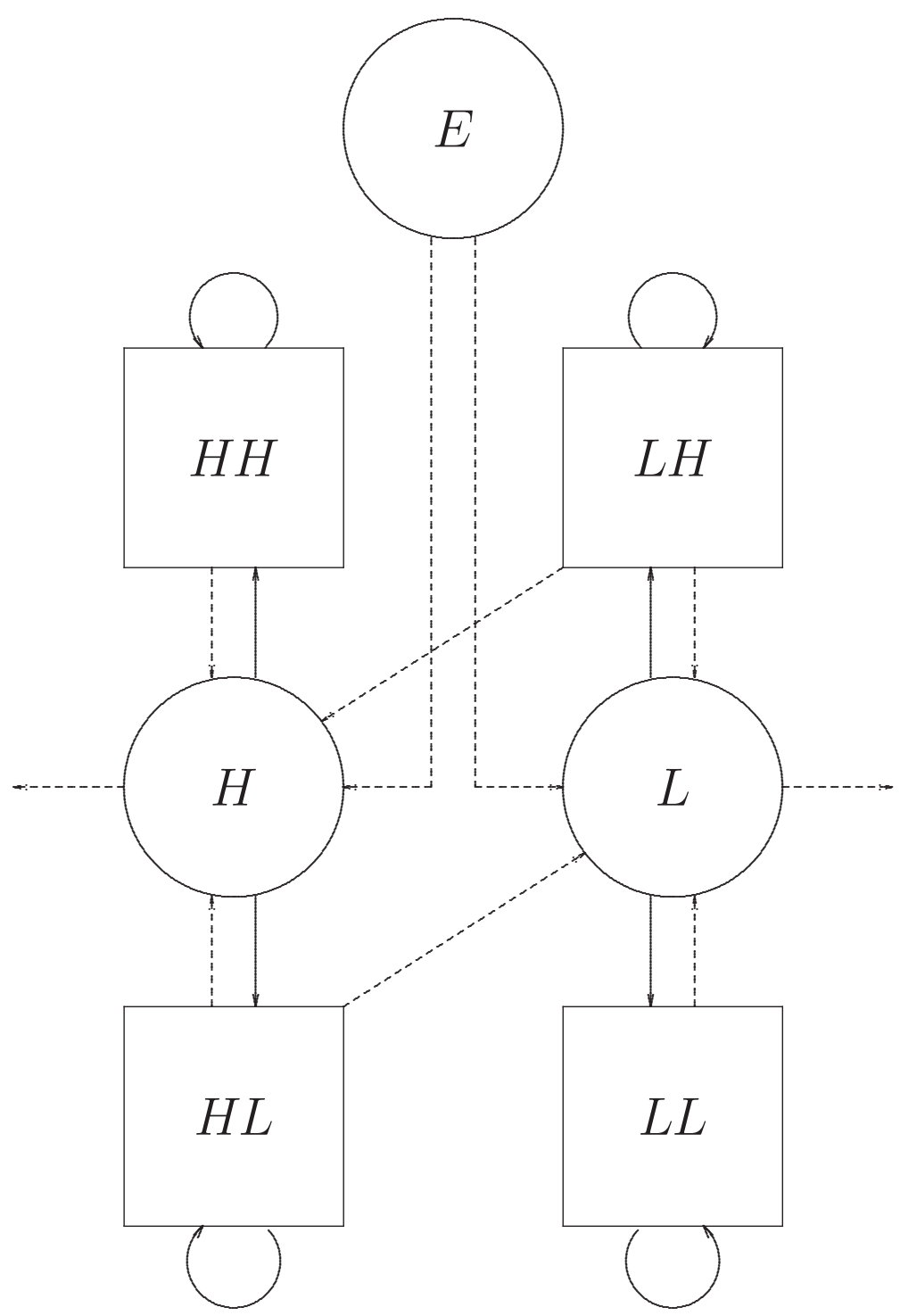

Figure 1: Firm and agent flows. 
can be of two types: solid arrows represent firm flows, whereas dashed arrows represent agent flows. For example, the circular arrow in box $H H$ indicates that a fraction of the $H H$ type firms in period $t$ remain $H H$ type firms in period $t+1$. The dashed arrow going out of the $H H$ box indicates that, if a $H H$ type firm decides to exit, then there is a flow into the bin of $H$ type agents. These agents may either exit the industry altogether, as denoted by the dashed line to the left of the $H$ bin, or they may create a new firm. Depending on whether they hire a worker of type $H$ or type $L$, this will create a firm flow into the $H H$ or $H L$ bin, respectively.

\section{Equilibrium}

The model presented in the previous section, together with a set of decision rules by managers and workers, leads to a dynamic path of $\mu_{z}^{t}(z=$ $H H, H L, L H, L L)$, the measure of firms of type $z$ in period $t$. We look for a situation where the values of $\mu_{z}$ are stable (time invariant). Specifically, a stationary equilibrium is defined by a set of measures of active firms $\mu_{z}$; a measure of new entrants $\nu$; and an industry price $p$ that satisfy a series of transition and optimality conditions:

1. Managers make optimal exit decisions given firm type $z$;

2. Workers make optimal spin-off decisions;

3. Potential entrants make optimal entry decision;

4. The flows of managers and firms are balanced;

5. The market clears: $p=P(Y)$, where $Y=\sum \mu_{z} y_{z}$.

Our main result pertains to the existence and properties of such an equilibrium.

Proposition 1 (stationary equilibrium) For an open set of parameter values, there exists a unique stationary equilibrium with the following properties:

(a) Firms choose to voluntarily exit if and only if their type is $z=L L$; 
(b) Workers attempt a spin-off if and only if their type is $H$ or their type is $L$ and they know the firm will exit.

The proof can be found in the Appendix. Note that part (b) of Proposition 1 refers to two different types of spin-off. A worker who learns he is of type $H$ is strictly better off by spinning-off, regardless of the parent firm's type; we call this a type I spin-off. Moreover, a worker who learns that the firm will exit by the end of the period is also strictly better off by spinning-off, regardless of his type; we call this a type II spin-off.

\section{Testable implications}

We now explore some implications of our model for the relation between spinoffs and firm performance. Given data availability, we consider an indirect measure of firm performance: survival rates. We are interested in the impact of spin-offs on the parent's and the new firm's survival rate. ${ }^{3}$

The next result provides three testable implications of our theory regarding spin-off performance. For the purpose of our paper, we define a surviving parent as one that continues in operation beyond the period when the spin-off takes place.

Proposition 2 (spin-off performance)

(a) Spin-offs originating from surviving parents survive with higher probability than de novo entrants.

(b) Spin-offs originating from surviving parents survive with higher probability than spin-offs originating from non-surviving parents.

(c) The survival rates of a spin-off originating from a surviving parent is independent of parent type.

3. Our model allows for the possibility of spin-offs initiated by firm owners. However, our analysis focuses on spin-offs initiated by former employees. The next two propositions refer to the latter type of spin-offs. 
Proof: A de novo entrant's manager is of type $H$ with probability $\alpha$; the manager of a spin-off firm originating from a surviving parent is of type $H$ with probability one (regardless of parent type); and the manager of a spinoff firm originating from a non-surviving parent is of type $H$ if probability strictly lower than one. The various results follow.

The following result provides three testable implications of our theory regarding parent performance.

\section{Proposition 3 (parent performance)}

(a) If a firm is of type $H H$, then its survival rate is invariant with respect to the occurrence of a spin-off.

(b) If a firm is not of type $\mathrm{HH}$, then its survival rate is lower conditional on giving birth to a spin-off.

(c) A firm's survival rate conditional on giving birth to an $L$ manager spin-off is lower than its survival rate conditional on giving birth to an $H$ manager spin-off.

Proof: (a) An $H H$ type firm only exits due to an exogenous shock, the probability of which is orthogonal to the event of a spin-off. (b) A firm of type $L H$ who loses its worker switches from $z=L H$ to $z=L L$ with probability $\rho(1-\alpha)$, in which case it exits. Otherwise, it remains at $z=L H$, in which case it does not voluntarily exit. A firm of type $H L$ only gives rise to a spin-off if it is about to exit due to an exogenous shock. (c) Finally, the only instance when a spin-off is initiated by an $L$ type worker is when its parent's exit is anticipated, in which case exit takes place with probability one. By contrast, a parent who gives birth to a spin-off initiated by an $H$ type worker experiences a death rate which is strictly lower than one.

Part (a) of Proposition 3 suggests that a high-type firm $(H H$ in our model) is less sensitive to a spin-off than other firms (in terms of survival rate). In our model, this results from the high level of managerial human capital in a high-type firm. In reality, however, firm size may also play a role. 


\section{Data and empirical results}

We test the implications of our model using a unique dataset of the U.S. automobile industry. The dataset covers U.S. companies that sold at least one automobile to the public during the industry's first 75 years (1895-1969), a total of 780 firms.

The data sources come from different industry references. First, Smith (1968) provides a list of every make of automobile produced commercially in the U.S. from the industry's beginnings in 1895 through 1969. ${ }^{4}$ The book lists the firm that manufactured each car make, the firm's location, the years the particular make was produced, and any reorganizations and ownership changes the firm underwent. Smith's list of car makes was then used to derive the entry and exit of each individual firm, where entry and exit dates are based on the first and last year of commercial production. As shown in Figure 2, the automobile industry went through a tremendous development during this period, evolving from a small infant industry into a gigantic, concentrated, mature industry. The number of automobile manufacturers peaked at 206 in 1908. From then and until the late 1920s there was a considerable industry shakeout, with the total number of firms dropping to 24 in 1929. Further consolidation took place, and by 1940 there were only 8 active firms. Despite the overall boom-and-bust cycle, we note that, as happens in many other industries (e.g., Dunne et al, 1988) the net entry/exit rate is much lower than the turnover rate, that is, we observe simultaneous entry and exit in the industry pretty much at all stages.

Second, Kimes (1996) provides comprehensive historical information for every automobile make produced in the U.S. from 1890-1942. Using Kimes (1996), we are able to collect additional biographical information about the entrepreneurs who founded and ran each individual firm. An entrepreneur was then categorized into several groups. One group includes those entrepreneurs who had prior experience in engineering, mechanics or other technologically related industries. Another group includes experienced entrepreneurs who founded or ran firms before entering the automobile industry. Still another group includes spin-off entrepreneurs, that is, entrepreneurs

4. The original book published in 1968 was updated to include information up to 1969. 


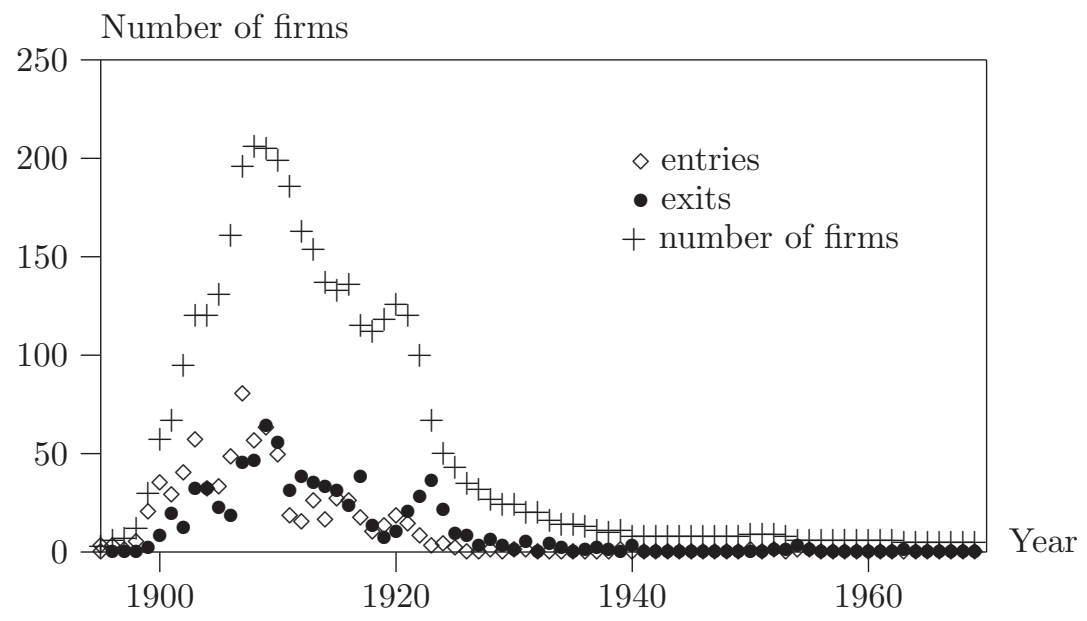

Figure 2: Evolution of the U.S. automobile industry, 1895-1969.

who worked as employees in existing automobile firms before starting their own firm. The last group consists of de novo entrepreneurs, namely those with no identifiable background. Note that these groups are not mutually exclusive: for example, someone might have run a non-automobile firm and also worked as an employee in an automobile firm before starting his own automobile company. In that case, he is categorized as both an experienced entrepreneur and a spin-off. Figure 3 splits the number of entries into spinoffs and other entries. (We restrict to the period 1895-1925, when the number of entrants was significant.) As can be seen, after the first industry shakeout (circa 1910), the number of spin-off entrants and other entrants is of the same order of magnitude.

Third, Bailey (1971) provides a list of leading automobile makes from 1896-1970 based on top-15 annual sales. Using this information, together with the other two sources, we are able to identify top automobile producers during the relevant periods.

In summary, we put together a dataset including the following information:

1. The entry year of each firm;

2. The exit year of each firm; 


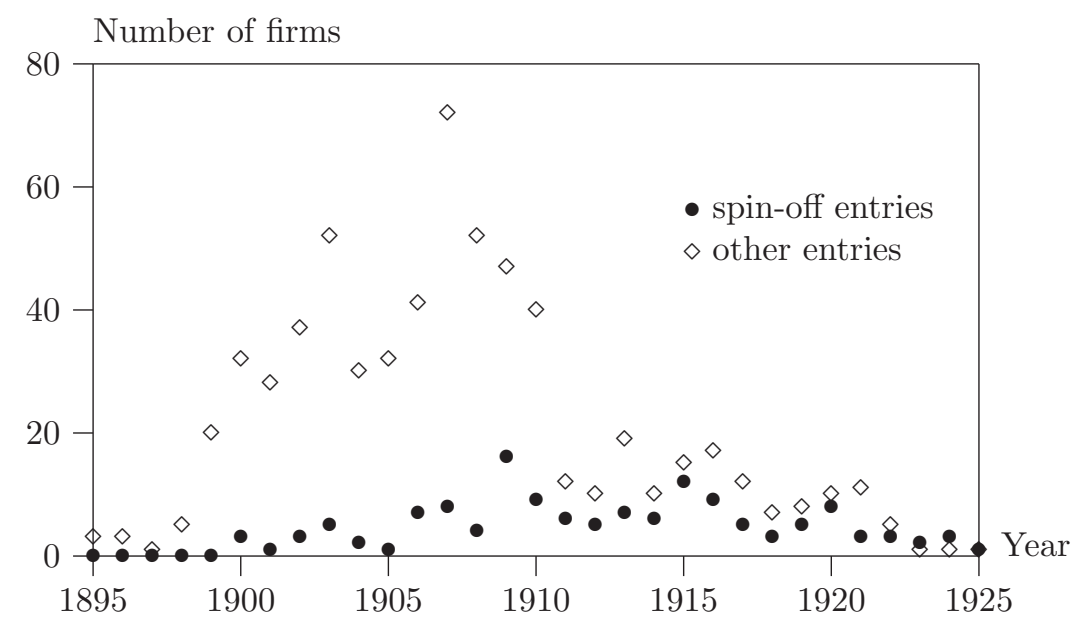

Figure 3: Evolution of the U.S. automobile industry, 1895-1925.

3. The type of each firm exit, that is, whether the firm exited by liquidation or by merger or acquisition;

4. The background of each entrepreneur mapped into four categories, including spin-offs, de novo entrants, entrepreneurs with technological background and experienced entrepreneurs;

5. The quality of each firm in terms of producing top makes in the industry or not;

6. The firm's location.

Using the above information, we created the following dummy variables (indexed by firm and year). Whenever the definition of the variable is not obvious, an explanation is given.

- Firm died in current period. In our base regressions, we exclude the cases when a top firm merged or was acquired. ${ }^{5}$ There were 15 such observations, about $2 \%$ of the total number of exits.

5. In our robustness section, we explain our choice and show it has little impact on our results. 
- Firm is Top. The firm was classified as the producer of a top car make during at least one year in the sample. ${ }^{6}$ (In terms of our theoretical model, we think of a Top firm as an $H H$ type.)

- Firm is Bottom. The firm is not a Top firm.

- Firm was created as a spin-off. The firm's founder worked for another auto manufacturer prior to founding the firm.

- Firm was spun-off from Top parent.

- Firm was spun-off from Bottom parent.

- Firm was spun-off from Bottom surviving parent. A surviving parent is defined as one that was active for at least 2 years after the spin-off took place.

- Firm was spun-off from Bottom non-surviving parent.

- Firm is Top and gave birth to spin-off.

- Firm is Bottom and gave birth to spin-off.

- Firm is Bottom and gave birth to Good spin-off. A Good spin-off is defined as one that survives for more than 1 year.

- Firm is Bottom and gave birth to Bad spin-off. A Bad spin-off is defined as one that survives for only 1 year or less.

- Founder's background is technology related.

- Founder's background is entrepreneurial related.

In addition, we created the following variables:

- Firm age.

- Year.

6. In our robustness section, we use different definitions of this variable and obtain similar results. 
- Region. We created seven regional dummies corresponding to: Great Lakes, Mid Atlantic, Michigan, Mid West, New England, South, and West.

Table 2: Descriptive statistics (firm level data).

\begin{tabular}{|c|c|c|c|c|}
\hline Variable & Mean & Std Dev & Min & $\operatorname{Max}$ \\
\hline Firm was created as a spin-off & 0.177 & 0.382 & 0 & 1 \\
\hline $\begin{array}{l}\text { Firm was spun-off from Top par- } \\
\text { ent }\end{array}$ & 0.071 & 0.257 & 0 & 1 \\
\hline $\begin{array}{l}\text { Firm was spun-off from Bottom } \\
\text { parent }\end{array}$ & 0.106 & 0.308 & 0 & 1 \\
\hline $\begin{array}{l}\text { Firm was spun-off from Bottom } \\
\text { surviving parent }\end{array}$ & 0.080 & 0.271 & 0 & 1 \\
\hline $\begin{array}{l}\text { Firm was spun-off from Bottom } \\
\text { non-surviving parent }\end{array}$ & 0.026 & 0.159 & 0 & 1 \\
\hline Firm is Top & 0.061 & 0.239 & 0 & 1 \\
\hline $\begin{array}{l}\text { Founder's background is tech- } \\
\text { nology related }\end{array}$ & 0.466 & 0.499 & 0 & 1 \\
\hline $\begin{array}{l}\text { Founder's background is en- } \\
\text { trepreneurial related }\end{array}$ & 0.375 & 0.484 & 0 & 1 \\
\hline Entry year & 1908 & 6.3 & 1895 & 1939 \\
\hline
\end{tabular}

- Descriptive statistics. Tables 2 and 3 provide some descriptive statistics of the main variables we created, both at the firm level and at the firm $\times$ year level. From Table 2 (firm level data), we can see that about $17.7 \%$ of all firm entries took place as spin-offs from existing firms (7.1\% from Top parents, $8.0 \%$ from Bottom surviving parents, and 2.6\% from Bottom nonsurviving parents). About $6.1 \%$ of firms are Top. Almost one half of firm founders had a technology related background; more than a third had previous entrepreneurial experience.

From Table 3, we can see that the firm death rate is about $17.2 \%$ per year. This is somewhat higher than a typical exit rate in mature industries 
(e.g., Dunne et al, 1988), which is only normal given that we are analyzing a growing industry, where the level of turnover is typically higher. We also see that the average age of a firm is just under 7 years.

Table 3: Descriptive statistics (firm $\times$ year level data).

\begin{tabular}{|l|r|r|r|r|}
\hline Variable & Mean & Std Dev & Min & Max \\
\hline \hline Firm died in current period & 0.172 & 0.378 & 0 & 1 \\
\hline Firm was created as a spin-off & 0.199 & 0.400 & 0 & 1 \\
\hline $\begin{array}{l}\text { Firm was spun-off from Top par- } \\
\text { ent }\end{array}$ & 0.106 & 0.308 & 0 & 1 \\
\hline $\begin{array}{l}\text { Firm was spun-off from Bottom } \\
\text { parent }\end{array}$ & 0.093 & 0.291 & 0 & 1 \\
\hline $\begin{array}{l}\text { Firm was spun-off from Bottom } \\
\text { surviving parent }\end{array}$ & 0.072 & 0.259 & 0 & 1 \\
\hline $\begin{array}{l}\text { Firm was spun-off from Bottom } \\
\text { non-surviving parent }\end{array}$ & 0.021 & 0.144 & 0 & 1 \\
\hline \hline Firm is Top & 0.197 & 0.398 & 0 & 1 \\
\hline $\begin{array}{l}\text { Firm is Top and gave birth to } \\
\text { spin-off }\end{array}$ & 0.010 & 0.099 & 0 & 1 \\
\hline $\begin{array}{l}\text { Firm is Bottom and gave birth } \\
\text { to spin-off }\end{array}$ & 0.010 & 0.098 & 0 & 1 \\
\hline $\begin{array}{l}\text { Firm is Bottom and gave birth } \\
\text { to Good spin-off }\end{array}$ & 0.007 & 0.084 & 0 & 1 \\
\hline $\begin{array}{l}\text { Firm is Bottom and gave birth } \\
\text { to Bad spin-off }\end{array}$ & 0.002 & 0.050 & 0 & 1 \\
\hline $\begin{array}{l}\text { Founder's background is tech- } \\
\text { nology related }\end{array}$ & 0.532 & 0.499 & 0 & 1 \\
\hline $\begin{array}{l}\text { Founder's background is en- } \\
\text { trepreneurial related }\end{array}$ & 0.452 & 0.498 & 0 & 1 \\
\hline \begin{tabular}{l} 
Firm age \\
\hline Year
\end{tabular} & 6.821 & 7.168 & 1 & 43 \\
\hline \hline Nire of & 8.4 & 1895 & 1942 \\
\hline
\end{tabular}

Number of observations: 4457 
- Regressions. We ran a series of logit regressions using firm-year observations with Firm died in current period as the dependent variable. The basic logit model is equivalent to a discrete-time duration model under the assumption that the baseline hazard is constant over time. However, by including firm age and year effects, we allow the hazard rate to vary over time. The inclusion of year effects also addresses the potential problem that the automobile industry underwent a major shakeout during the period we run our regressions.

The data range is from 1895-1942, including 776 firms and 4457 firm-year observations. $^{7}$ In each regression, we divide the set of explanatory variables into two sets. The first set corresponds to the variables that have a direct bearing on the testable implication included in Propositions 2 and 3. The second set corresponds to additional variables that we would expect to have an influence of firm survival. We could have developed a more complex theoretical model to account for those effects but chose rather to stick to the main focus in the paper: the relation between parent and spin-off performance.

Table 4 presents results from our first regression. In this regression, we consider three variables that address the implications of Propositions 2 and 3. Part (a) of Proposition 2 suggests that the coefficient of the variable Firm was created as a spin-off should be negative. ${ }^{8}$ The second and third explanatory variables directly test parts (a) and (b) Proposition 3. Specifically, we expect the coefficient of Firm is Top and gave birth to spin-off to be zero and the coefficient of Firm is Bottom and gave birth to spin-off to be positive: when a Bottom firm gives birth to a spin-off, either the spin-off is a type II spin-off, in which case the parent exits (bail-out effect); or the parent loses valuable talent in a type I spin-off, which in turn increases the exit probability (depletion effect).

7. Given the information provided in Kimes (1996), we collect biographical information about the entrepreneurs up to 1942, before the U.S. entered WWII.

8. Strictly speaking, part (a) of Proposition 2 states that spin-offs of surviving parents perform better than de novo entrants. Spin-offs originating from non-surviving firms are started by both type $H$ and type $L$ entrepreneurs, and so, theoretically, their survival rate could be greater or lower than a de novo entrant. However, as we have seen, the summary statistics show that most spin-offs originate in surviving parents. We conclude that Proposition 2 can also be read unconditionally on parent's survival. In our next regression, we further test and confirm this interpretation. 
Table 4: Spin-off and parent performance.

\begin{tabular}{|l|r|r|r|c|}
\hline \multicolumn{5}{|l|}{ Dependent variable: Firm died in current period } \\
\hline \hline Explanatory variables & Coef. & Std. Err. & $z$ & $P>|z|$ \\
\hline \hline Firm was created as a spin-off & -0.243 & 0.129 & -1.88 & 0.060 \\
\hline $\begin{array}{l}\text { Firm is Top and gave birth to } \\
\text { spin-off }\end{array}$ & -0.088 & 1.035 & -0.08 & 0.932 \\
\hline $\begin{array}{l}\text { Firm is Bottom and gave } \\
\text { birth to spin-off }\end{array}$ & 0.866 & 0.321 & 2.70 & 0.007 \\
\hline \hline Firm is Top & -2.092 & 0.229 & -9.15 & 0.000 \\
\hline $\begin{array}{l}\text { Founder's background is } \\
\text { technology related }\end{array}$ & -0.313 & 0.097 & -3.23 & 0.001 \\
\hline $\begin{array}{l}\text { Founder's background is } \\
\text { entrepreneurial related }\end{array}$ & -0.275 & 0.090 & -3.07 & 0.002 \\
\hline Firm age & -0.015 & 0.010 & -1.56 & 0.119 \\
\hline Year & 0.021 & 0.007 & 2.99 & 0.003 \\
\hline Constant & -41.211 & 13.424 & -3.07 & 0.002 \\
\hline \hline Number of observations: 4443 & & & & \\
\hline
\end{tabular}

The results are consistent with these predictions. The coefficient of Firm was created as a spin-off is negative and significant at the $6.0 \%$ level. The coefficient of Firm is Top and gave birth to spin-off is not significantly different from zero. Finally, the coefficient of Firm is Bottom and gave birth to spin-off is positive and significant at the $0.7 \%$ percent level.

In order to get a feel for the economic magnitude of these coefficients, we also computed their associated odds ratios. The odds ratio for Firm was created as a spin-off is given by .7845 . This implies that the ratio $d /(1-d)$, where $d$ is the death rate, is $(1-0.7845)$ lower for spinoff firms. Specifically, given that the sample average death rate of non-spinoff firms is $17.77 \%$, our model predicts that the average death rate of a spin-off firm is $14.50 \%$ (in other words, the death rate drops by 18\%). The odds ratio of Firm is Bottom and gave birth to spin-off is given by 2.3774. This implies that the ratio $d /(1-d)$ is $(2.3774-1)$ higher for Bottom firms who give birth to 
spinoff firms than for other Bottom firms. Specifically, given that the sample average death rate of Bottom firms who do not give birth is $20.16 \%$, our model predicts that the average death rate of Bottom firms who give birth to a spin-off is $37.51 \%$ (in other words, the death rate increases by $86 \%$ ).

The remaining explanatory variables have the signs we would expect. Many models of firm entry and exit predict that larger and/or more profitable firms survive with higher probability, leading to a negative coefficient for Firm is Top, as the results indeed suggest. ${ }^{9}$ Any model with experience effects would predict a positive coefficient for the variables Founder's background is technology related and Founder's background is entrepreneurial related. Again, the results confirm the expectation.

Table 5 reports on the results of a second regression. We now "split" the variable Firm was created as a spin-off into three variables: Firm was spun-off from Top parent, Firm was spun-off from Bottom surviving parent, and Firm was spun-off from Bottom non-surviving parent. Part (b) of Proposition 2 implies that the coefficient of Firm was spun-off from Bottom non-surviving parent be greater than the coefficient of Firm was spun-off from Bottom surviving parent. Part (c) of Proposition 2 implies that the coefficient of Firm was spun-off from Top parent and Firm was spun-off from Bottom surviving parent be the same.

The results are again consistent with the theory. Both the coefficients of Firm was spun-off from Top parent and Firm was spun-off from Bottom surviving parent are negative and significantly different from zero (if marginally). Since the coefficients are not statistically different from each other and are of similar magnitude, we ran a separate regression imposing the same coefficient on both variables, as our theory suggests. The coefficient's estimate is now -.276 and statistical significance level increases considerably, with a $p$ value of 0.042 .

The coefficient of Firm was spun-off from Bottom non-surviving parent is close to zero and in fact is not statistically different from zero. Since the omitted case is de novo entry, the results suggest that a spin-off from a dying parent is not different, in terms of post-entry performance, than a de novo

9. For simplicity, in our theoretical model we assumed the value of $\gamma$ (the probability of a Nature exit shock) is the same for all firm types. We could easily have chosen type-specific values of $\gamma$ to obtain different exit probabilities. 
entrant. Finally, the above values also imply that the coefficient of Firm was spun-off from Bottom surviving parent is lower than the coefficient of Firm was spun-off from Bottom non-surviving parent, as predicted by theory.

Table 5: Spin-off and parent performance.

\begin{tabular}{|l|r|c|c|c|}
\hline Dependent variable: Firm died in current period \\
\hline \hline Explanatory variables & Coef. & Std. Err. & $z$ & $P>|z|$ \\
\hline \hline $\begin{array}{l}\text { Firm was spun-off from Top } \\
\text { parent }\end{array}$ & -0.295 & 0.189 & -1.56 & 0.119 \\
\hline $\begin{array}{l}\text { Firm was spun-off from } \\
\text { Bottom surviving parent }\end{array}$ & -0.263 & 0.164 & -1.61 & 0.108 \\
\hline $\begin{array}{l}\text { Firm was spun-off from } \\
\text { Bottom non-surviving parent }\end{array}$ & -0.047 & 0.269 & -0.18 & 0.860 \\
\hline $\begin{array}{l}\text { Firm is Top and gave birth to } \\
\text { spin-off }\end{array}$ & -0.081 & 1.035 & -0.08 & 0.937 \\
\hline $\begin{array}{l}\text { Firm is Bottom and gave } \\
\text { birth to spin-off }\end{array}$ & 0.874 & 0.321 & 2.72 & 0.006 \\
\hline \hline Firm is Top & -2.079 & 0.233 & -8.91 & 0.000 \\
\hline $\begin{array}{l}\text { Founder's background is } \\
\text { technology related }\end{array}$ & -0.315 & 0.097 & -3.25 & 0.001 \\
\hline $\begin{array}{l}\text { Founder's background is } \\
\text { entrepreneurial related }\end{array}$ & -0.272 & 0.090 & -3.03 & 0.002 \\
\hline Firm age & -0.015 & 0.010 & -1.56 & 0.119 \\
\hline Year & 0.021 & 0.007 & 2.97 & 0.003 \\
\hline Constant & -41.329 & 13.542 & -3.05 & 0.002 \\
\hline \hline Number of observations: 4443 & & & \\
\hline
\end{tabular}

Table 6 reports on the results of a third regression. This time we "split" the variable Firm is Bottom and gave birth to spin-off into two: Firm is Bottom and gave birth to Good spin-off and Firm is Bottom and gave birth to Bad spin-off. Being a Bad spin-off is positively correlated with the founder's being a low type worker. According to our theory, the only case when a low type worker starts a spin-off is when he expects the parent to exit (type II 
spin-off). Consequently, we expect the coefficient on Firm is Bottom and gave birth to Bad spin-off to be greater than the coefficient on Firm is Bottom and gave birth to Good spin-off.

Table 6: Spin-off and parent performance.

\begin{tabular}{|l|r|r|r|c|}
\hline \multicolumn{5}{|l|}{ Dependent variable: Firm died in current period } \\
\hline \hline Explanatory variables & Coef. & Std. Err. & $z$ & $P>|z|$ \\
\hline \hline Firm was created as a spin-off & -0.246 & 0.129 & -1.90 & 0.057 \\
\hline $\begin{array}{l}\text { Firm is Top and gave birth to } \\
\text { spin-off }\end{array}$ & -0.087 & 1.035 & -0.08 & 0.933 \\
\hline $\begin{array}{l}\text { Firm is Bottom and gave } \\
\text { birth to Good spin-off }\end{array}$ & 0.469 & 0.398 & 1.18 & 0.238 \\
\hline $\begin{array}{l}\text { Firm is Bottom and gave } \\
\text { birth to Bad spin-off }\end{array}$ & 1.897 & 0.633 & 3.00 & 0.003 \\
\hline \hline Firm is Top & -2.093 & 0.229 & -9.16 & 0.000 \\
\hline $\begin{array}{l}\text { Founder's background is } \\
\text { technology related }\end{array}$ & -0.309 & 0.097 & -3.19 & 0.001 \\
\hline $\begin{array}{l}\text { Founder's background is } \\
\text { entrepreneurial related }\end{array}$ & -0.278 & 0.090 & -3.09 & 0.002 \\
\hline Firm age & -0.015 & 0.010 & -1.53 & 0.126 \\
\hline Year & 0.021 & 0.007 & 2.97 & 0.003 \\
\hline Constant & -41.003 & 13.436 & -3.05 & 0.002 \\
\hline \hline Number of observations: 4443 & & & & \\
\hline
\end{tabular}

As mentioned earlier, we define a Good spin-off as one that survives for more than one year. We tried different thresholds and decided that one year was best. Ideally, the split should be such that a Good spin-off from a Bottom firm performs as well as a spin-off from a Top firm. The average life span of a spin-off from a Top firm is 6.96 years, whereas the average life span of a spin-off from a Bottom firm is 4.90 years (lower, as expected). Among the latter, if we exclude spin-offs who survived for one year or less, the average life span increases to 6.56 years. If we also exclude spin-offs who survived for two years, then the average life span increases to 7.57 years. 
The results reported in Table 6 confirm our prediction. The coefficient on Firm is Bottom and gave birth to Bad spin-off is positive, large, and significantly different from zero. The coefficient on Firm is Bottom and gave birth to Good spin-off, by contrast, is not statistically different from zero. Nevertheless, the coefficient is positive, as predicted by the depletion effect of type I spin-offs. Moreover, consistently with parts (a) and (b) of Proposition 3, the coefficient on Firm is Bottom and gave birth to Good spin-off is higher than the coefficient on Firm is Top and gave birth to spin-off.

Robustness checks. While our base results correspond to a limited number of regression equations, we find them to be fairly robust. We performed a series of robustness checks. First, in our base definition of exit, we exclude high-type firm exits by merger or acquisition. The idea is that merging with or being acquired by another firm may reflect good performance rather than poor performance. We repeated the same regressions with the alternative definition that includes all exits. The results are very similar to our base results.

Second, in our base regressions we estimate the impact of spin-offs on parent performance by considering contemporaneous effects only. Alternatively, we may also consider one-year lagged effects. The results are again very similar.

Third, we re-estimated the results on a sub-sample consisting of years 1910-1942. Figure 3 suggests that this was a period where de novo and spinoff entry patterns were more stable. We obtain similar results to those on the 1895-1942, although, as expected, the levels of statistical significance are lower.

Fourth, we consider various definitions of Top firms. In our base regressions, we count a firm as a Top firm if it ever made the top annual sale list in Bailey (1971). Alternatively, a firm may be counted as Top during a time window $N$ years before and after it made it to the top sales list (or until a spin-off occurred). We experimented different values of $N$ and the results were quite similar.

Fifth, we considered a variety of additional possible controls, including year and regional dummies. The results are very similar. Finally, we also considered the possibility of firm fixed effects. Our random-effect logit panel 
regressions yield very similar results to our basic regressions. ${ }^{10}$

\section{Concluding remarks}

Our model of passive learning about firm type and worker type, while relatively simple, leads to a rich set of implications regarding spin-off performance, parent performance, and the relation between spin-off and parent performance. In particular, our theory predicts a high correlation between spin-offs and parent exit, especially when the parent is a low-productivity firm. This correlation may correspond to two types of causality. Whenever the spin-off is motivated by a worker learning that he would be a good entrepreneur (type I spin-off), the spin-off implies a depletion effect (good talent leaves the parent), which increases the probability of parental death. Whenever a worker learns that his employer is unlikely to survive for very long, the opportunity cost of starting a new firm becomes lower and all types of worker leave the firm to start a new one (type II spin-off).

We tested our theory on a unique dataset from the US automobile industry. Our empirical findings provide support for the various predictions derived from our theoretical model. While we chose the automobile industry as an application, we would expect our results to be more widely applicable.

Our paper sheds new light on policy discussions regarding spin-offs. We are among the first ones to investigate the effect of spin-offs on the survival of their parents (see also Campbell et al, 2009). Our results refine the existing literature regarding "covenant not to compete" type laws by considering spinoffs motivated by passive learning. We show that, while such spin-offs are likely to decrease the value and survival of parent firms, their outcome is nevertheless socially beneficial, as they optimally reallocate human capital. In other words, we argue that the view of spin-offs as pure business stealing is incomplete.

10. Results from all of these alternative regressions are available from the authors upon request. 


\section{Appendix}

Proof of Proposition 1: We need to check the following equilibrium conditions:

- $L L$ firms prefer to exit, whereas all other types prefer to remain active.

- Insider agents, regardless of type, prefer to start a new firm rather than exiting the industry. By "insider" we mean that the agent has already paid the initial learning cost, so that creating a new firm costs $\phi$, whereas first-time entrants need to pay an entry cost $\psi+\phi$.

- $H$ workers prefer to attempt a spin-off, whereas $L$ workers prefer to remain in employment. ${ }^{11}$

Essentially, these conditions require that $\psi$ be very high (e.g., there is a large learning cost of getting into the industry), $\pi_{L L}$ is very low whereas the remaining $\pi_{z}$ are high; and $\omega$ has an intermediate value.

We proceed as follows. First, we write out the value functions for managers, entrepreneurs and workers. Then we impose the required equilibrium inequalities on these value functions. Finally, we show there exists an open set of parameter values satisfying the equilibrium conditions.

Value functions. Let $V_{z}$ be the value of owning a firm of type $z(z=$ $H H, H L, L H, L L)$. Let $V_{i}$ be the value of a type $i$ insider agent $(i=H, L)$ who does not currently hold a secure job in the industry. Let $V_{E}$ be the value of a potential entrant. Finally, let $W_{i}$ be the value of a currently employed worker of type $i(i=H, L)$.

At a stationary equilibrium, because there is exit, there must also be entry. Since there is an infinite measure of potential entrants, each entrant must be indifferent between entering and not entering, the latter yielding the outside option value $\xi$. This implies that

$$
\xi=\alpha V_{H}+(1-\alpha) V_{L}-\psi
$$

11. Throughout, we assume that the worker's wage is sufficiently high that being a worker (including the option of becoming an entrepreneur) is better than the outside option. 
and $V_{E}=\xi$. As to the value of insider agents, we have

$$
\begin{aligned}
& V_{H}=\rho\left(\alpha V_{H H}+(1-\alpha) V_{H L}\right)+(1-\rho) \xi-\phi \\
& V_{L}=\rho\left(\alpha V_{L H}+(1-\alpha) V_{L L}\right)+(1-\rho) \xi-\phi
\end{aligned}
$$

The value $V_{z}$ of owning a firm of type $z$ is given by

$$
\begin{aligned}
& V_{H H}=\pi_{H H}+\delta\left(\gamma\left((1-\rho+\rho \alpha) V_{H H}+\rho(1-\alpha) V_{H L}\right)+(1-\gamma) V_{H}\right) \\
& V_{H L}=\pi_{H L}+\delta\left(\gamma V_{H L}+(1-\gamma) V_{H}\right) \\
& V_{L H}=\pi_{L H}+\delta\left(\gamma\left((1-\rho+\rho \alpha) V_{L H}+\rho(1-\alpha) V_{L L}\right)+(1-\gamma) V_{L}\right) \\
& V_{L L}=\pi_{L L}+\delta V_{L}
\end{aligned}
$$

where $\delta$ is the discount factor. The linear system formed by (2) and (3) yields unique values $\left\{V_{z}\right\}(z=H, L, H H, H L, L H, L L)$ as functions of model parameters $\alpha, \rho, \gamma, \delta, \phi, \psi, \xi$ and $\pi_{z}$. (Recall that $\pi_{z}=p y_{z}-\omega$.) Finally, substituting for $V_{H}$ and $V_{L}$ in (1), and simplifying, we get

$$
\alpha^{2} V_{H H}+\alpha(1-\alpha) V_{H L}+(1-\alpha) \alpha V_{L H}+(1-\alpha)^{2} V_{L L}=\xi+\frac{\psi+\phi}{\rho}
$$

Transition equations. Let $\mu_{z}$ be the measure of firms of type $z$ and $\nu$ the measure of new entrants. In a stationary equilibrium, we have:

$$
\begin{gathered}
\mu_{H H}=\mu_{H H}(\gamma(1-\rho)+2 \rho \alpha)+\mu_{H L}(1-\gamma) \rho \alpha+\mu_{L H} \rho \alpha+\nu \alpha^{2} \\
\mu_{H L}=2 \mu_{H H} \rho(1-\alpha)+\mu_{H L}(\gamma+(1-\gamma) \rho(1-\alpha))+ \\
+\mu_{L H} \rho(1-\alpha)+\nu \alpha(1-\alpha) \\
\mu_{L H}=\mu_{H L}(1-\gamma) \rho \alpha+\mu_{L H}(\rho \alpha+\gamma(1-\rho))+ \\
\quad+2 \mu_{L L} \rho \alpha+\nu \alpha(1-\alpha) \\
\mu_{L L}=\mu_{H L}(1-\gamma) \rho(1-\alpha)+\mu_{L H} \rho(1-\alpha)+ \\
+2 \mu_{L L} \rho(1-\alpha)+\nu(1-\alpha)^{2}
\end{gathered}
$$

This linear system induces a unique solution $\left\{\mu_{z}\right\}$ as a function of $\nu$ and parameters $\alpha, \rho, \gamma, \delta$.

Equilibrium price and measure of entrants. Substituting the solution to (2)-(3) into (4) and simplifying, we get

$$
c_{1} p-c_{2}=0
$$


where $c_{1}$ is a function of $\alpha, \rho, \gamma, \delta$ as well as the values of $y_{z}$; and $c_{2}$ is a function of $\alpha, \rho, \gamma, \delta$ as well as the values of $\omega, \psi, \phi$ and $\xi$. Moreover $c_{1}>0$ and $c_{2}>0$.

Substituting the solution of (5) for $\mu_{z}$ in the industry output equation, $Y=\sum \mu_{z} y_{z}$ we get

$$
Y=c_{3} \nu
$$

where $c_{3}$ is a function of $\alpha, \rho, \gamma, \delta$ and the values of $y_{z}$; and moreover $c_{3}>0$.

From (7), we see that, as $\nu$ ranges from zero to $\infty$, so does $Y$. Therefore, as $Y$ varies from zero to $\infty, p$ varies from $\infty$ to zero. From (6), it follows that there exist unique $\nu$ and $p$ satisfying (6)-(7).

We next look at the equilibrium constraints regarding each agent's decision.

Firm's exit decision. Consider the decision of an $L L$ firm. By deciding to remain active, rather than exit, such firm would expect a value $V_{L L}=$ $\pi_{L L}+\delta V_{L}$, as given by (3). We therefore impose the condition $V_{L} \geq \pi_{L L}+\delta V_{L}$, or simply

$$
V_{L} \geq \frac{\pi_{L L}}{1-\delta}
$$

By a similar argument, we conclude that the condition $V_{H L} \geq V_{H}$ reduces to

$$
V_{H} \leq \frac{\pi_{H L}}{1-\delta}
$$

The expressions become more complicated as we consider firms with an $H$ worker. For $L H$, we can solve (3) to get

$$
\begin{aligned}
V_{L H}=(1-\delta \gamma(1-\rho(1-\alpha)))^{-1} & \\
& \left(\pi_{L H}+\delta \rho(1-\alpha) \pi_{L L}+\left(\delta^{2} \rho(1-\alpha)+(1-\gamma)\right) V_{L}\right)
\end{aligned}
$$

We require that $V_{L H} \geq V_{L}$, which is equivalent to

$$
V_{L} \leq \frac{\pi_{L H}+\delta \rho(1-\alpha) \pi_{L L}}{1-\delta(\gamma+(2-3 \gamma) \rho(1-\alpha))}
$$


As for firm $H H$, we can solve (3) to get

$$
\begin{aligned}
V_{H H}=(1-\delta \gamma(1-\rho(1-\alpha)))^{-1} & \\
& \left(\pi_{H H}+\delta \rho(1-\alpha) \frac{1}{1-\delta \gamma}\left(\pi_{H L}+\delta(1-\gamma) V_{H}\right)(1-\gamma) V_{H}\right)
\end{aligned}
$$

We require that $V_{H H} \geq V_{H}$, which is equivalent to

$$
V_{H} \leq \frac{\pi_{H H}+\frac{\delta \rho(1-\alpha)}{1-\delta \gamma} \pi_{H L}}{\gamma-\delta \gamma(1-\rho(1-\alpha))-\frac{\delta^{2}(1-\gamma) \rho(1-\alpha)}{1-\gamma}}
$$

Compare the right-hand side of this inequality to that of (9): the numerator is higher, whereas the denominator is lower. It follows that (11) is implied by (9).

Worker's spin-off decision. Consider now an worker's decision when employed by a continuing firm. Let $W_{i}$ be the value of such worker, where $i=H, L$ is his type. If the worker decides to attempt a spin-off, then $W_{i}=V_{i}$. If instead the worker decides to remain in employment, then $W_{i}=\omega+\delta\left(\gamma W_{i}+(1-\gamma) V_{i}\right)$, or simply

$$
W_{i}=\frac{\omega+\delta(1-\gamma) V_{i}}{1-\delta \gamma}
$$

We therefore impose the twin conditions

$$
\begin{aligned}
V_{H} & \geq \frac{\omega+\delta(1-\gamma) V_{H}}{1-\delta \gamma} \\
V_{L} & \leq \frac{\omega+\delta(1-\gamma) V_{L}}{1-\delta \gamma}
\end{aligned}
$$

which simplify into

$$
V_{L} \leq \frac{\omega}{1-\delta} \leq V_{H}
$$

$\square$ Insider's decision. An insider must decide whether to attempt creating a firm or rather taking the outside option $\xi$. Our equilibrium assumption is that all insiders attempt to create a firm. This implies

$$
V_{L} \geq \xi
$$


Since $V_{H}>V_{L}$, the condition $V_{H} \geq \xi$ is implied by the condition $V_{L} \geq \xi$.

Parameter values satisfying equilibrium conditions. The claim is that there exists an open set of parameter values such that the equilibrium outline above exists. The key equilibrium conditions are: (8), (9), (10), (12), (13). Suppose that $\alpha=\frac{1}{2} ; \gamma=\delta=\rho=.9 ; \xi=0, \phi=1, \psi=10$; $\pi_{L L}=0-\omega, \pi_{L H}=5-\omega, \pi_{H L}=6-\omega, \pi_{H H}=7-\omega$; and $\omega=1$. Then all of the five inequalities are satisfied strictly. This shows there is an open set of parameter values satisfying the equilibrium conditions. Notice that we are arbitrating the revenue portion of $\pi_{z}$, which is endogenous. In fact, $\pi_{z}=p y_{z}-\omega$, where $p$ is endogenous. However, by appropriately changing the demand curve, we can obtain any value of equilibrium price. So, starting with primite values of $y_{z}$, we can change the demand curve and obtain values of $p y_{z}$ that maintain the initial proportions. So we can simply assume $y_{L L}=0, y_{L H}=5, y_{L H}=6, y_{L H}=7$; and the above values are then derive from primitive parameter values. Alternatively, for a given demand curve, we can change the values of $y_{z}$ proportionately with respect to the values above. 


\section{References}

Baccara, Mariagiovanna, and Ronny Razin (2006), "The Relationship between Innovation and Governance," New York University and London School of Economics.

Bailey, L.S. (1971), The American Car since 17r5, Automobile Quarterly: New York.

Campbell, Benjamin, Martin Granco, April Franco, and Rajshree Agarwal (2009), "Who Leaves, to Go Where and Does It Matter? Employee Mobility, Employee Entrepreneurship, and the Effects on Parent Firm Performance," Ohio State University, University of Illinois, and University of Toronto.

Chatterjee, SAtyajit, And Esteban Rossi-Hansberg (2007), "Spin-Offs and the Market for Ideas," Federal Reserve Bank of Philadelphia and Princeton University.

Dunne, Timothy, Mark Roberts and Larry Samuelson (1988), "Patterns of firm entry and exit in U.S. manufacturing industries," Rand Journal of Economics 19, 494-515.

Franco, April, And Darren Filson (2006), "Spin-Outs: Knowledge Diffusion Through Employee Mobility," Rand Journal of Economics 37, 841-860.

Franco, April, and Matthew Mitchel (2008), "Covenants not to Compete, Labor Mobility, and Industry Dynamics," Journal of Economics and Management Strategy 17, 581-606.

Jovanovic, Boyan (1982), "Selection and Evolution of Industry," Econometrica 50, 649-670.

KLepper, Steven (2002), "The capabilities of new firms and the evolution of the US automobile industry," Industrial and Corporate Change 11, 645-666.

Klepper, S, And S Slepper (2002), "Entry by Spin-offs," Papers on Econonmics and Evolution 2002-07, Max Planck Institute of Economics, Evolutionary Economics Group.

KlePPer And Thompson (2005), "Spinoff Entry in High-tech Industries: Motives and Consequences," Working Papers 0503, Florida International University, Department of Economics. 
Klepper And Thompson (2006), "Intra-Industry spinoffs," Working Papers 0605, Florida International University, Department of Economics..

Kimes, Beverly R. (1996), Standard Catalog of American Cars, 1890-1942, third edition, Iola, WI: Krause Publications Inc.

Smith, PhiLiP H. (1968), Wheels within Wheels, New York: Funk and Wagnalls. 